https://doi.org/10.37208/tgn27120

\section{Defensive behaviour in the scotch argus Erebia aethiops (Lepidoptera: Nymphalidae)}

\author{
I.C. Wilkie
}

Institute of Biodiversity, Animal Health and Comparative Medicine, University of Glasgow, Glasgow G12 8QQ

E-mail: iain.wilkie@glasgow.ac.uk

Animals perform a huge variety of defensive behaviours when disturbed by predators and other agents. One type that has a wide taxonomic distribution is the passive dropping response, whereby a sudden and rapid descent is effected under the force of gravity alone. Perhaps the best-known example of this is shown by flying noctuid and geometrid moths, which close their wings and go into "free-fall" when they detect ultrasound patterns characteristic of closely approaching bats (Nakano \& Mason, 2018). Whilst dropping responses are employed by animals as diverse as brittlestars (Echinodermata:
Ophiuroidea) (Emson \& Wilkie, 1982) and young gazelles (Mammalia: Bovidae) (Walther, 1969), they are particularly prevalent amongst terrestrial arthropods. They have been observed in arachnids, including spiders (Tolbert, 1975) and an acarid, the sheep tick Ixodes ricinus (I.C. Wilkie, pers. obs.), and in a range of insects other than moths, including aphids (Hemiptera) (Harrison \& Preisser, 2016), bush crickets (Orthoptera) (Libersat \& Hoy, 1991), and lacewings (Neuroptera) (Miller, 1984). In many of these cases, the dropping response is displayed by animals that are initially attached to a substrate (e.g. a silk web or vegetation) and therefore, of necessity, it is preceded by the animal releasing its grip. The present contribution provides information on a dropping response of this type, which was observed in a familiar butterfly and which appears not to have been previously described.

The scotch argus Erebia aethiops (Esper, 1777) (Fig. 1A) is widespread and locally abundant over sheltered, moist grasslands in Scotland, with only two colonies occurring further south in England in the Lake District (Thomas \& Lewington, 2016). Since the 1970s it has shown "a modest decrease in occurrence and a significant increase in abundance" (Fox et al., 2015) and is therefore, in terms of conservation concerns, regarded as being of low priority.
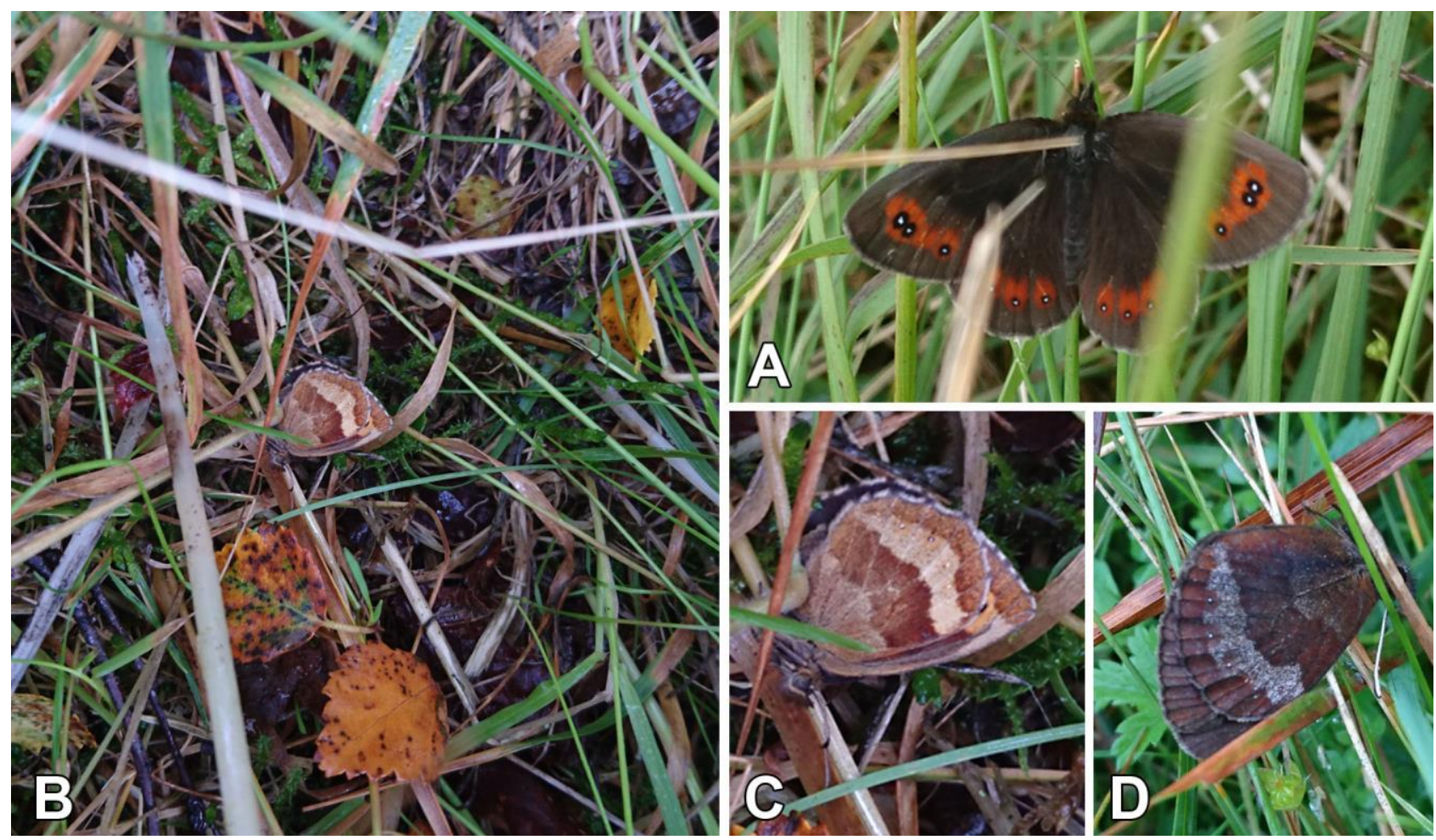

Fig. 1. Scotch argus (Erebia aethiops), Argyll, Scotland, August 2018. (A) Dorsal view of a resting individual, Creagan an Eich, Strachur. (B, C) Female, photographed immediately after completing the dropping response. Note the shed birch leaves. (D) Male, photographed immediately after completing the dropping response. (Photos: I.C. Wilkie) 
On 7th August 2018 on the southwestern slope of Creagan an Eich near Strachur, Argyll (VC98) at an elevation of around $130 \mathrm{~m}$, I saw a female scotch argus resting with open wings amongst long grass in an exposed situation just above a secondary birch wood (Betula pubescens). Although on sunny days these are very active butterflies and difficult to approach closely, this was a dull day and the insect did not at first react as I moved towards it. Eventually, however, when I disturbed the nearby vegetation it suddenly closed its wings and dropped down through the grass, settling on one side and remaining motionless with the visible hindwing almost completely overlapping the forewing and concealing most of the eyespot on the latter (Fig. 1B,C). After a few seconds it became active again, righting itself and crawling with closed wings over the grass leaves. I then deliberately agitated the vegetation near it again and it responded as before, falling onto one side and remaining motionless with overlapping wings (the eyespot on the forewing being completely concealed this time). When it righted itself and started to move, I repeated the exercise once more, producing the same result. On a subsequent dull day - 16th August 2018 - at a nearby location, I elicited the same response from a resting male scotch argus, which, when disturbed, fell on one side and remained motionless with closed wings (Fig. 1D). It is therefore likely that landing on one side is not accidental but an integral component of the defensive response.

Assuming that the primary function of this behaviour is predator avoidance, it would be especially effective in this particular location and at this particular time of the year, because the nearby birch trees had started to shed leaves. The colours of the undersurfaces of the butterflies' wings were within the range of colours shown by shed birch leaves, and the size (i.e. planar dimensions) of the closed wings was within the range of sizes shown by the birch leaves. The resemblance between the underside of the wings of this species and dead leaves has been previously noted (Haggart, 1895). Predator avoidance in the scotch argus thus appears to comprise five components: detachment from the substrate, passive dropping, settling on one side, immobilisation, and leaf-masquerading ("masquerading" being defined as "resembling an inedible or unexciting object": Stoddard, 2012). As this has been inferred from observations on only two individuals, it of course requires corroboration.

It is unlikely that this pattern of defensive behaviour, if verified, would be unique to the scotch argus. The first two components of the adult behaviour are also shown by scotch argus caterpillars (Haggart, 1895), and by the caterpillars of other species with leaf-like camouflage, such as the grayling (Hipparchia semele) and meadow brown (Maniola jurtina) (Thomas \& Lewington, 2016). It would be interesting to know if the adults of any of these other species also employ a dropping response.

Active scotch argus have been described as "diving for cover as soon as the sun becomes obscured..." (Emmet $\&$ Heath, 1990). This behaviour must be invoked by visual or thermal stimuli. In contrast, it is not known if the putative dropping response is triggered by mechanical or visual signals associated with agitated vegetation, nor if agitation characteristic of approaching predators can be distinguished from that due to abiotic factors, such as wind and rain.

I am grateful to Tony Payne and an external reviewer for drawing my attention to relevant literature.

\section{REFERENCES}

Emmet, A.M. \& Heath, J. (Editors) (1990). The Moths and Butterflies of Great Britain and Ireland. Vol. 7, pt. 1: Hesperiidae - Nymphalidae (The Butterflies). Harley Books, Colchester.

Emson, R.H. \& Wilkie, I.C. (1982). The arm-coiling response of Amphipholis squamata (delle Chiaje). In: Lawrence, J.M. (Editor). Echinoderms: Proceedings of the International Conference, Tampa Bay, pp. 11-18. Balkema, Rotterdam.

Fox, R., Brereton, T.M., Asher, J., August, T.A., Botham, M.S., Bourn, N.A.D. et al. (2015). The State of the UK's Butterflies 2015. Butterfly Conservation and the Centre for Ecology \& Hydrology, Wareham, Dorset.

Haggart, J.C. (1895). Observations on Erebia aethiops (blandina). The Entomologist 28, 297-298.

Harrison, K.V. \& Preisser, E.L. (2016). Dropping behavior in the pea aphid (Hemiptera: Aphididae): how does environmental context affect antipredator responses? Journal of Insect Science 16, 1-5. https://doi.org/10.1093/jisesa/iew066

Libersat, F. \& Hoy, R.R. (1991). Ultrasonic startle behaviour in bushcrickets (Orthoptera: Tettigoniidae). Journal of Comparative Physiology A 169, 507-514. https://doi.org/10.1007/BF00197663

Miller, L.A. (1984). Hearing in green lacewings and their responses to the cries of bats. In: Canard, M., Séméria, Y. \& New, T.R. (Editors). Biology of Chrysopidae, pp.134-149. Dr W. Junk Publishers, The Hague.

Nakano, R. \& Mason, A.C. (2018). Early erratic flight response of the lucerne moth to the quiet echolocation calls of distant bats. PLOS ONE 13(8), e0202679.

https://doi.org/10.1371/journal. pone.0202679

Stoddard, M.C. (2012). Mimicry and masquerade from the avian perspective. Current Zoology 58, 630-648. https://doi.org/10.1093/czoolo/58.4.630

Thomas, J. \& Lewington, R. (2016). The Butterflies of Britain and Ireland. Bloomsbury, London.

Tolbert, W.W. (1975). Predator avoidance behaviors and web defensive structures in the orb weavers Argiope aurantia and Argiope trifasciata (Araneae, Araneidae). Psyche 82, 29-52. https://doi.org/10.1155/1975/39173

Walther, F.R. (1969). Flight behaviour and avoidance of predators in Thomson's gazelle (Gazella Thomsoni Guenther 1884). Behaviour 34, 184-221. https://doi.org/10.1163/156853969X00053 